Published in final edited form as:

Public Health Nutr. 2021 August ; 24(11): 3552-3565. doi:10.1017/S1368980021000707.

\title{
Association between hourly wages and dietary intake after the first phase of implementation of the Minneapolis minimum wage ordinance
}

\author{
Leah Elizabeth Chapman ${ }^{1,2}$, Seth A. Berkowitz ${ }^{3}$, Alice Ammerman ${ }^{1,2}$, Molly De Marco ${ }^{1,2}$, \\ Shu Wen $\mathrm{Ng}^{1,4}$, Catherine Zimmer ${ }^{5}$, Caitlin E. Caspi ${ }^{6,7}$ \\ 1.Department of Nutrition, Gillings School of Global Public Health, University of North Carolina at \\ Chapel Hill, 135 Dauer Drive, Chapel Hill, NC 27599 \\ 2. Center for Health Promotion \& Disease Prevention, University of North Carolina at Chapel Hill, \\ 1700 M.L.K. Jr Blvd \#7426, Chapel Hill, NC, 27514 \\ 3.General Medicine and Clinical Epidemiology, University of North Carolina at Chapel Hill, 5034 \\ Old Clinic Building, CB 7110, Chapel Hill, NC 27599 \\ 4.Carolina Population Center, University of North Carolina at Chapel Hill, 123 West Franklin \\ Street, Chapel Hill, NC 27516 \\ 5. Odum Institute, University of North Carolina at Chapel Hill, 208 Raleigh St, Chapel Hill, NC \\ 27514 \\ 6.UConn Rudd Center for Food Policy and Obesity, 1 Constitution Plaza, Hartford, CT \\ Minneapolis, MN 06103 \\ 7.Allied Health Sciences, University of Connecticut, Storrs, CT, 06268
}

\section{Abstract}

Objective: In 2018, Minneapolis began phased implementation of an ordinance to increase the local minimum wage to $\$ 15 /$ hour. We sought to determine whether the first phase of implementation was associated with changes in frequency of consumption of fruits and vegetables, whole grain-rich foods, and foods high in added sugars among low-wage workers.

Design: Natural experiment.

Setting: The Wages Study is a prospective cohort study of 974 low-wage workers followed throughout the phased implementation of the ordinance (2018-2022). We used difference-indifference analysis to compare outcomes among workers in Minneapolis, Minnesota, to those in a

\footnotetext{
Corresponding author: Leah Elizabeth Chapman, 135 Dauer Drive, 245 Rosenau Hall, CB \# 7461, Chapel Hill, North Carolina 27599, leahchapman@unc.edu, (352) 215-8332 (phone), (919) 966-7678 (fax).

Authorship: Caitlin Caspi obtained funding for the study and designed the study. Caitlin Caspi and Molly De Marco led the implementation of the study. Leah Chapman and Seth Berkowitz analyzed the quantitative data. Leah Chapman wrote the first draft with contributions from Seth Berkowitz. All authors reviewed and commented on the subsequent drafts of the manuscript. Conflict of Interest: Seth Berkowitz reports receiving personal fees from the Aspen Institute, outside of the submitted work.

Ethical Standards Disclosure: This study was conducted according to the guidelines laid down in the Declaration of Helsinki and all procedures involving research study participants were approved by the University of Minnesota Institutional Review Board and the University of North Carolina at Chapel Hill Institutional Review Board. Written informed consent was obtained from all subjects.
} 
comparison city (Raleigh, North Carolina). We assessed wages using participants' pay stubs and dietary intake using the National Cancer Institute Dietary Screener Questionnaire.

Participants: Analyses use the first two waves of Wages data (2018 [baseline], 2019) and includes 267 and 336 low-wage workers in Minneapolis and Raleigh (respectively).

Results: After the first phase of implementation, wages increased in both cities, but the increase was $\$ 0.82$ greater in Minneapolis $(\mathrm{p}=0.02)$. However, the first phase of the policy's implementation was not associated with changes in daily frequency of consumption of fruits and vegetables (IRR=1.03, 95\% CI: $0.86-1.24, \mathrm{p}=0.73)$, whole grain-rich foods $(\mathrm{IRR}=1.23,95 \% \mathrm{CI}$ : $0.89-1.70, \mathrm{p}=0.20$ ), or foods high in added sugars (IRR=1.13, 95\% CI: 0.86-1.47, $\mathrm{p}=0.38$ ) among workers in Minneapolis compared to Raleigh.

Conclusions: The first phase of implementation of the Minneapolis minimum wage policy was associated with increased wages, but not with changes in dietary intake. Future research should examine whether full implementation is associated dietary changes.

\section{Keywords}

minimum wage; natural experiment; social policy; dietary intake

\section{Introduction:}

Disparities in dietary intake are a major focus of public health research, practice, and policy in the United States (U.S.). On average, low-income Americans have lower intakes of fruits and vegetables $(\mathrm{F} \& \mathrm{~V})$ and lower quality diets than higher income Americans. ${ }^{(1,2)}$ Higher cost of healthier foods may contribute to these disparities. ${ }^{(3-5)}$ Therefore, policies that increase hourly wage for lower income Americans' could increase household income ${ }^{(6)}$ and thus, the ability to purchase healthier, often more costly foods such as F\&V.

In June 2017, Minneapolis, Minnesota passed an ordinance that will incrementally increase the minimum wage above the state level to $\$ 15$ an hour, from $\$ 9.50$ per hour for all businesses with greater than 100 employees, and from $\$ 7.75$ per hour in smaller businesses. (12) The incremental annual wage increase must be fully implemented by July $1^{\text {st }}, 2022$ for large businesses and two years later for small businesses (Figure 1). ${ }^{(12)}$

Because minimum wage increases could increase income for lower-wage workers, they could improve diet quality as affording healthier food becomes more possible. However, it is unclear if minimum wage ordinances actually translate to higher household income (because other changes in household income related and unrelated to the minimum wage may occur). Further, even if income does increase, it is not clear that additional income would be used for healthier food purchases. It is also unclear whether an increase in household income would cause participants to experience a reduction in their federal food assistance, or reduce their hours worked. Figure 2 presents a conceptual model that displays various hypothesized relationships between a minimum wage ordinance and improvements in dietary intake.

Three prior cross-sectional studies have examined associations between minimum wage increases and F\&V consumption, but had mixed results. ${ }^{(9-11)}$ Horn et al. found no 
association between minimum wage increases and the daily number of $\mathrm{F} \& \mathrm{~V}$ consumed in lesser-skilled female workers, and found an inverse association among males. ${ }^{(9)}$ Similarly, Andreyeva \& Ukert found that a one-dollar wage increase was associated with a 0.17 percent reduction in F\&V consumption. ${ }^{(10)}$ In contrast, a 2020 study by Clark et al. estimated an increase of approximately 0.08 daily $\mathrm{F} \& \mathrm{~V}$ servings when the minimum wage increased by one dollar. ${ }^{(11)}$ However, these cross-sectional studies used proxy measures such as education and household income to approximate the likelihood of being affected by minimum wage increases, rather than measuring this directly. Thus a longitudinal study that follows groups exposed, and unexposed, to a legislated minimum wage increase and directly measures hourly wage is needed.

The aim of this study is to examine whether the first phase of a minimum wage increase in Minneapolis is associated with changes in frequency of consumption of $\mathrm{F} \& \mathrm{~V}$, whole grainrich foods (in which a food's first ingredient is a whole grain), and foods high in added sugars ( $>5$ grams of sugar per serving) among low-wage workers. We hypothesized that the minimum wage ordinance would be associated with increased wages and household income, and would be associated with improvements in dietary intake.

\section{Methods:}

\section{Study Population:}

The Wages study is a prospective cohort study. Recruitment methods and inclusion criteria are described in detail elsewhere. ${ }^{(13)}$ In January 2018, the Wages Study began following a cohort of 974 low-wage workers (those earning $\$ 11.50$ an hour at baseline) in Minneapolis $(\mathrm{n}=495)$ and low-wage workers in a comparison city with no minimum wage increase (Raleigh, North Carolina, $\mathrm{n}=479$ ). The study aims to follow this cohort throughout 4.5 -years of implementation of the Minneapolis minimum wage ordinance (January 1, 2018-July 1, 2022). Recruitment and baseline data collection occurred from January-October 2018. Of note, the baseline data collection period (hereon referred to as Wave 1) was extended from the original completion date of July 2018 to October 2018 due to challenges in recruitment. Details of this are discussed elsewhere. ${ }^{(13)}$ Wave 2 data collection occurred during the summer and fall of 2019. Data will be collected again in the summers of 2020 (Wave 3), 2021 (Wave 4), and 2022 (Wave 5).

This study described in this manuscript uses the first two waves of longitudinal data from the currently ongoing Wages Study ( $\mathrm{n}=655$, as 319 participants of the originally recruited 974 participants were lost to follow-up at Wave 2). After exclusions, data from 603 Wages participants at Waves 1 and 2 were available for the study's first set of analyses (Figure 3), and 540 Wages participants were available for the second set of analyses (Figure 4). The study was approved by the institutional review boards of the University of Minnesota and the University of North Carolina at Chapel Hill, and participants gave written informed consent to participate. 


\section{Hourly Wage Assessment:}

Wages participants attend one data collection appointment each year in which wages are verified and a computer-based survey is administered. Participants are asked to bring a recent pay stub or other document from their primary employer to verify their hourly wage at the annual data collection appointment. At Wave 1, 75.67\% of participants verified their hourly wage (737/974). At Wave 2, 81.37\% of the 655 participants who returned for a follow-up appointment verified their hourly wage (533/655). All other participants selfreported their hourly wage.

\section{Dietary Assessment:}

To assess dietary intake, the computer-administered survey included 22 questions from the validated 26-item National Cancer Institute's (NCI) Dietary Screener Questionnaire (DSQ). $(14,15)$ The primary investigators for the Wages research team excluded four DSQ items from the computer survey (milk, cheese, red meat, and processed meat) because the research team wanted to keep only the most relevant questions in the computer survey to minimize participant survey fatigue.

For the current analysis, we used the DSQ frequency data to estimate participants' daily frequency of intake of three different food groups to be used as the study's dependent variables: $\mathrm{F} \& \mathrm{~V}$, whole grain-rich foods (in which the first ingredient is a whole grain), and foods high in added sugars ( $>5$ grams of sugar per serving). These food groups were created because all three are associated with weight gain (a lower risk for $F \& V^{(16)}$ and whole grainrich foods ${ }^{(17)}$ and a higher risk for foods high in added sugars $\left.{ }^{(18,19)}\right)$ and chronic disease risk (a reduced risk for $\mathrm{F} \& \mathrm{~V}^{(20)}$ and whole grain-rich foods ${ }^{(21)}$ and an increased risk for foods high in added sugars $\left.{ }^{(2)}\right)$ in previously conducted scientific literature. The five-gram cutoff was chosen for foods high in added sugars because the Daily Value (DV) of added sugars is 50 grams per day based on a 2,000 kilocalorie per day diet, ${ }^{(23)}$ and the Food and Drug Administration considers a food to be a "good" source of a nutrient if it contains 10-19\% of the DV. ${ }^{(24)}$ Thus, we designated a food as being high in added sugar if it contained more than $10 \%$ DV for sugar (greater than 5 grams). Supplemental Table 1 displays the foods from the DSQ that contribute to each food group.

To create the food group dependent variables, the research team first classified all foods from the DSQ as to whether they belonged, or not, in each of the three food groups. Foods could belong to more than one food group. We then converted participants' responses to the DSQ into daily frequencies for each food (for example, if a participant responded that he/she consumed popcorn " $2-3$ times last month," we divided 2.5 by 30 and assigned that participant a value of 0.083 for their popcorn consumption variable). Finally, we created three new variables for each participant in the data set. The first variable was the sum of the daily frequencies for all $F \& V$ foods, the second variable was the sum of the daily frequencies for all whole grain-rich foods, and the third was the sum of the daily frequencies for all foods high in added sugars. 


\section{Covariate Assessment:}

We collected data on demographic, economic, and health-related factors including age (continuous), sex (male, female, non-binary), race (white alone, black or African American alone, Asian alone, Native Hawaiian or Pacific Islander alone, Native American or Alaskan native alone, more than one race, or other race), ethnicity (Hispanic/Latino, non-Hispanic/ Latino), marital status (married or single), birthplace (born in the U.S., born abroad to American parents, or born abroad), whether or not a participant was a food service worker (as food service employees are often provided meals on the job, ${ }^{(25)}$ which may impact their dietary intake), educational attainment (less than high school, some high school, high school diploma, associate/technical degree, some college, or Bachelor's degree or higher), number of adults living in the household (one, two, three, four, or five or more), number of children living in the household (one, two, three, four, or five or more), pregnancy status (pregnant, not pregnant), smoking status (current smoker, quit less than 12 months ago, quit more than 12 months ago, or never smoker), health insurance status (insured all year [any type of health insurance], uninsured for at least part of the year, or uninsured all year), BMI (continuous), the timing (in weeks) of the participant's data collection appointment relative to the minimum wage increase, number of jobs worked (one job worked or more than one job worked), and the amount received in Supplemental Food and Nutrition Assistance Program (SNAP) benefits (I do not receive any SNAP benefits, $\$ 1-\$ 25, \$ 26-\$ 50$, $\$ 51-$ $\$ 75, \$ 76-\$ 100, \$ 101-\$ 150, \$ 151-\$ 250, \$ 251-\$ 500, \$ 501-\$ 750$, more than $\$ 750)$.

\section{Statistical Analysis:}

The research team performed two sets of difference-in-difference (DID) analyses to address the present study's aims. The first DID analysis examined whether living in a city with a mandated minimum wage increase was associated with changes in daily frequency of F\&V consumption (model one), whole grain-rich foods (model two), and foods high in added sugars (model three). This analysis categorized participants by city of residence ( $0=$ Raleigh, $1=$ Minneapolis) when assessing the exposure in the DID models. We term these the "policy" analyses. The second analysis examined whether changes in individual hourly wage were associated with changes in daily frequency of $\mathrm{F} \& \mathrm{~V}$ consumption (model four), whole grainrich foods (model five), and foods high in added sugars (model six). This analysis used Wages participants' hourly wage as the exposure variable in the DID models. We term these the "hourly wage" analyses.

The research team chose to conduct two sets of DID analyses for several reasons. First, the policy analysis examines the association between the change in policy and the change in outcome, acknowledging that some Wages participants in Minneapolis may not experience a wage increase from Wave 1 to Wave 2 (due to the possibility that some businesses may not be compliant in implementing the minimum wage ordinance, or due to the possibility that wage changes may not be linear and positive over time among low-wage workers, particularly if job changes, job losses, or a reduction in hours worked occur). This is important as it estimates the impact of the ordinance under "real-world" conditions of adherence. Additionally, participants in Raleigh may also experience wage increases (due to job promotions, raises, etc.). Lastly, it accounts for any impact of simply living in an area 
with a mandated wage increase on dietary outcomes (e.g. changing attitudes, beliefs, and norms). ${ }^{(26)}$ However, the research team also wanted to run models in which participants' individual hourly wage served as the primary predictor variable. This is important to test, as increasing hourly wage is the key mechanism by which a minimum wage ordinance may increase household income and therefore improve dietary intake (Figure 5). Prior to conducting these DID analyses, the research team examined the parallel trends assumption $^{(27)}$ using BRFSS SMART data ${ }^{(28)}$ (Figure 6) and found that current trends in dietary intake between the two cities did not differ meaningfully when comparing data from residents with incomes less than $\$ 35,000$ per year from 2005-2015. All analyses were conducted in Stata/IC (version 16.0, 2019, StataCorp LLC, College Station, Texas).

\section{Analysis 1- Policy Analysis:}

In the first DID analytic approach, the Wave 1 Wages data were designated as the pre-policy period, while Wave 2 served as the post-policy period. The treatment group consisted of the Minneapolis participants and the control group the Raleigh participants. A product term for these two variables provided the DID estimate (city * time period). For all models, analyses adjusted for the covariates listed above.

The DID models were estimated using negative binomial regression, as the outcomes were over-dispersed count data. Likelihood ratio tests that the dispersion parameter was equal to zero revealed that negative binomial models were a better fit than Poisson models. ${ }^{(29-31)}$ Data were analyzed with longitudinal regression analysis (generalized estimating equations [GEE] with clustering by the individual), using the Huber/White/sandwich estimator of variance and an autoregressive correlation matrix in order to account for repeated measures within individuals. ${ }^{(32)}$ Sensitivity analyses were performed, and results did not change when alternative correlation matrices were specified.

\section{Analysis 2- Hourly Wage Analysis:}

The second analytic approach was identical to the first analytic approach, except continuous DID models were specified and Wages participants' hourly wages, rather than city of residence, were used to calculate the DID indicator (hourly wage * time period). The researchers adjusted for the same covariates as done in the first set of analyses, except city was added as an additional covariate.

\section{Sensitivity Analyses:}

Given the study's high attrition rate and thus the possibility of selection bias and biased parameter estimates, ${ }^{(33)}$ we examined differential attrition by baseline measures of age, sex, race, ethnicity, educational attainment, and SNAP usage among those who returned for a Wave 2 appointment $(n=655)$ versus those who did not $(n=319)$ using t-tests and chi-square tests (Tables 3 and 4). We also conducted sensitivity analyses for both the "policy" analyses and the "hourly wage" analyses using inverse probability-of-censoring weights (IPCW). IPCW inversely weights regression analyses by the probability of participation (determined based on a logistic regression model for probability of participation given past history covariates and outcomes). ${ }^{(34-37)}$ This inflates the impact of underrepresented subjects, so we 
can observe associations that would have been observed if all subjects had stayed in the Wages study at Wave 2 (assuming the models are correctly specified). ${ }^{(4-43)}$

To perform IPCW, we first fit a logistic regression model to estimate the probability of not returning at Wave 2 based on baseline characteristics of age, sex, race, ethnicity, educational attainment, birthplace, marital status, number of children living in the household, SNAP usage, hourly wage, job type, and whether the participant lived in Minneapolis or Raleigh. We then used weights derived from this model to re-estimate the six DID regression models and the associations that would have been observed if all subjects from Wave 1 had remained in the study at Wave 2 . The six weighted DID models used 1/P as weights. All covariates used in the weighted DID models were identical to the covariates in the original unweighted DID models.

\section{Post-hoc Analyses:}

In the event that results were not as hypothesized and a minimum wage policy change was not associated with changes in dietary intake between the cities, the research team decided to conduct post-hoc analyses to understand why. We hypothesized that if results were null, perhaps the first phase of change in minimum wage policy did not translate to higher hourly wages or higher household income between the two cities. We therefore decided to examine the following post-hoc research questions: RQ1) on average, did the hourly wage significantly change between the cities from Wave 1 to Wave 2?; RQ2) were changes in hourly wage associated with changes in household income?; RQ3) on average, did household income categories significantly change between the cities from Wave 1 to Wave 2?; RQ4) was the policy associated with changes in hourly wage between the cities from Wave 1 to Wave 2?; and RQ5) was the policy associated with changes in household income categories between the cities from Wave 1 to Wave 2? Because only one year had passed between Waves 1 and 2, we did not inflation-adjust hourly wages in the post-hoc analyses. Figure 5 displays how we thought the change in policy would lead to change in wages and outcomes, and what relationship each set of post-hoc analyses tested.

To address post-hoc RQ1 (did the hourly wage significantly change between the cities from Wave 1 to Wave 2?), the research team performed data tabulations to examine the average wages and change in wages among Raleigh and Minneapolis participants at Waves 1 and 2. Additionally, we estimated unadjusted DID regressions using longitudinal regression analysis (GEE with clustering by the individual), and using Huber/White/sandwich estimator of variance and an autoregressive correlation matrix to adjust for the within-subject correlation.

Given that household income was an ordinal variable in our data set, the research team addressed RQ2 (were changes in hourly wage associated with changes in household income?) by estimating a multinomial logistic regression model. A multinomial logistic regression model was estimated rather than an ordinal logistic regression model because the proportional odds assumption was tested and violated. Standard errors were clustered at the level of the individual. 
Again, because household income was an ordinal variable, the research team addressed RQ3 (did household income categories significantly change between the cities from Wave 1 to Wave 2?) by estimating a DID ordinal logistic regression model with standard errors clustered at the level of the individual. The same DID product term was used as described in RQ1. The proportional odds assumption was tested and held.

The same DID model from RQ1 was used for RQ4 (was the policy associated with changes in hourly wage between the cities from Wave 1 to Wave 2?). However, the following covariates were added: race, sex, age, education level, job classification, and the number of job trainings completed during the past 12 months. These covariates were selected because they are associated with both hourly wages and living in a particular area in existing economic literature. ${ }^{(38,39)}$

To address RQ5 (was the policy associated with changes in household income categories between the cities from Wave 1 to Wave 2?), the research team estimated a multinomial logistic DID regression model because the proportional odds assumption was again violated. Standard errors were clustered at the level of the individual. The following covariates were included in the models: race, sex, age, number of adults living in the household, marital status, education level, job classification, and the number of job trainings completing during the last 12 months. ${ }^{(38,39)}$

\section{Results:}

At Wave 2, 655 out of 974 Wages participants (67.25 percent) returned for a follow-up appointment (attrition rate of 32.75 percent). For the study's "policy" analyses, we used Wages data from Waves 1 and 2 ( $n=655)$, but excluded participants who double enrolled in the Wages study $(n=1)$, made more than $\$ 11.50$ per hour at baseline and therefore did not meet the study's inclusion criteria for enrollment $(n=18)$, and were missing more than one response on the DSQ at either Waves 1 or 2 ( $n=33$ ). After exclusions, data from 603 Wages participants were available for the study's "policy" analyses (Figure 3). For the "hourly wage" analyses, we excluded the same participants as the "policy" analyses, but also excluded participants who had retired at Wave $2(n=3)$ and therefore had no hourly wage, participants who were unemployed and could not provide a pay stub or self-report hourly wage from their most recent job in the past six months $(n=33)$, and participants who were missing hourly wage information $(\mathrm{n}=27)$. After exclusions, data from 540 Wages participants were available for analyses (Figure 4).

Baseline demographic information for participants included in both sets of this study's analyses is presented in Table 1. The majority of Wages participants were black or African American, non-Hispanic, and had received at least a high school diploma or higher. The average wage at Wave 1 was $\$ 10.32$ per hour in Minneapolis and $\$ 9.36$ per hour in Raleigh. The average number of weekly hours worked at Wave 1 was 25.77 hours per week in Minneapolis and 32.52 hours per week in Raleigh.

Tables 2 and 3 display descriptive statistics about economic indicators for participants included in both sets of analyses. On average across the sites, the most common job type 
among participants was "Food Preparation and Serving," and the distribution of the different job types remained relatively constant between Waves 1 and 2. For both sites, the average number of hours worked each week increased from Wave 1 to Wave 2. Lastly, for both sites, the percent of participants who worked more than one job decreased from Wave 1 to Wave 2.

\section{Analysis 1- Policy Results:}

Table 4 displays average daily frequencies of consumption for each food group by city for each wave. On average, consumption decreased for all three food groups in both cities. Table 5 displays results from the multivariable DID longitudinal regression analyses. There were no significant differences between the cities for daily frequency of consumption of F\&V (IRR=1.03, 95\% CI: 0.86-1.24, $\mathrm{p}=0.73$ ), whole grain-rich foods (IRR=1.23, 95\% CI: 0.89 $1.70, \mathrm{p}=0.20$ ), or foods high in added sugars (IRR=1.13, 95\% CI: 0.86-1.47, $\mathrm{p}=0.38$ ) (Table $5)$.

\section{Analysis 2- Hourly Wage Results:}

Table 4 displays average daily frequencies of consumption for each food group by city for each wave. Again, on average, consumption decreased for all three food groups in both cities. Results from the continuous multivariate DID longitudinal regression analyses indicated that there were no significant differences between the cities for daily frequency of consumption of $\mathrm{F} \& \mathrm{~V}$ (IRR=0.98, 95\% CI: 0.94-1.02, $\mathrm{p}=0.32$ ), whole grain-rich foods (IRR=0.97, 95\% CI: $0.91-1.05, \mathrm{p}=0.48)$, or foods high in added sugars (IRR $=1.01,95 \% \mathrm{CI}$ : $0.97-1.06, \mathrm{p}=0.57$ ) (Table 5).

\section{Sensitivity Analyses Results:}

Prior to performing our sensitivity analyses, the research team first used t-tests and chisquare tests to examine differences in baseline measures of age, sex, race, ethnicity, educational attainment, and SNAP usage among those who returned for a Wave 2 appointment $(n=655)$ versus those who did not $(n=319)$. There were no significant differences in age, race, ethnicity, educational attainment, or SNAP usage, but baseline measures of sex were significantly different between the groups (Supplemental Table 2). A higher percentage of females returned for a Wave 2 appointment. Supplemental Table 3 presents results from the sensitivity analyses using IPCW. Results did not change and remained null for all models when inverse probability weights were incorporated into the DID regression models.

\section{Post-hoc Analysis Results:}

First, we examined whether the policy's intended target, hourly wage, changed on average between the cities from Wave 1 to Wave 2. Based on data tabulations, the average hourly wage in Minneapolis was $\$ 10.32$ at Wave 1 and $\$ 12.73$ at Wave 2, equating to an average increase of $\$ 2.41$. In Raleigh, the average hourly wage at Wave 1 was $\$ 9.36$ and $\$ 10.93$ at Wave 2, resulting in an average increase of $\$ 1.57$. Thus, on average, the hourly wage increased in both Minneapolis and Raleigh, but it increased by 84 cents more in Minneapolis ( $\mathrm{p}=0.02$, based on t-test, data not shown). Similarly, results from the DID linear regression 
(RQ1- did the hourly wage significantly change between the cities from Wave 1 to Wave 2?) indicated that on average, the hourly wage significantly increased from Wave 1 to Wave 2, and it increased significantly more in Minneapolis than in Raleigh ( $\beta=0.82,95 \%$ CI: $0.13-$ $1.51, \mathrm{p}=0.02$, Table 6).

Changes in hourly wage were associated with changes in household income for higher categories of income ( $\mathrm{p}<0.001$ for income categories 4, 5, 6, 7 compared to income category 1, Table 6, RQ2- were changes in hourly wage associated with changes in household income?). Household income increased overall from Wave 1 to Wave 2; on average, participants had a 47 percent higher odds of moving into one higher household income category from Wave 1 to Wave 2 ( $\mathrm{p}<0.001$, Table 6, RQ3- did household income categories significantly change between the cities from Wave 1 to Wave 2?). However, there was no significant difference in changes in household income between the cities $(\mathrm{p}=0.23$, Table 6 , RQ3).

Results from the multivariate DID linear regression post-hoc analysis (RQ4- was the policy associated with changes in hourly wage between the cities from Wave 1 to Wave 2?) indicated that a change in wage policy was significantly associated with a change in hourly wage ( $p=0.03$, Table 6 ). However, a change in wage policy was not significantly associated with changes in any of the household income categories (Table 6, RQ5- was the policy associated with changes in household income categories between the cities from Wave 1 to Wave 2?).

\section{Discussion:}

This study found that, among low-wage workers in an area with policy-mandated minimum wage increase, the first phase of policy implementation was not associated with changes in daily frequency of consumption of $\mathrm{F} \& \mathrm{~V}$, whole grain-rich foods, or foods high in added sugars compared with low-wage workers in a control setting. Post-hoc analyses indicated that, on average, hourly wage increased after one year in both cities, but the increase was greater in Minneapolis than in Raleigh. However, this differential increase in hourly wage did not translate to differential increases in household income between the cities. Similarly, post-hoc analyses using multivariable DID regression found that living in a city with a minimum wage increase was associated with increases in hourly wage, but not increases in household income categories. Given that increased household income may be the key mechanism by which a higher mandated minimum wage could improve dietary intake, ${ }^{(40)}$ the lack of change in household income between the cities may explain why there were no significant changes in dietary intake after the first year of implementation.

There are several potential reasons household income did not increase more in Minneapolis than Raleigh. First, perhaps the partially implemented policy did affect household income, but our categorical income measure was not sensitive enough to detect it. Second, it is possible that the minimum wage policy did not affect household income because of unintended consequences of the policy, such as reduced hours for workers. However, we did not find that this was the case, as average hours worked increased from $\sim 30$ hours per week at Wave 1 to $\sim 33$ hours per week at Wave 2. Third, perhaps the policy did not affect 
household income differentially between the cities because it is impacted by so many other non-policy-related components, including other household members' income and childcare situations.

Interestingly, consumption of all three food groups decreased from Waves 1 to 2 (based on raw tabulations of the data). The decrease in consumption may be attributable to a number of factors. First, these decreases may have been due to regression to the mean. Additionally, it is possible that the DSQ contains measurement error, and a more comprehensive measure of dietary intake, such as 24-hour recalls, may have better captured changes in mean intake over time. However, validation studies have shown close agreement when comparing mean values from nutrients and food groups between the DSQ and 24-hour recall data (gold standard) for both males and females. ${ }^{(15)}$ The research team therefore chose to administer the DSQ rather than 24-hour recalls and instead invest our resources into obtaining precise hourly wage data (using open-ended response questions for our hourly wage variable and asking for paystub verification) because this was the variable that the policy was directly targeting.

An additional explanation as to why consumption decreased is that perhaps SNAP benefits decreased among some participants at Wave 2. SNAP benefits inversely track with household income; given that wages and household income increased in both cities at Wave 2, some loss of benefits was expected. However, the amount of SNAP benefits participants received did not significantly change between Waves 1 and 2 overall or when stratified by city (based on an ordinal logistic regression model, Supplemental Table 4). Despite this, even small changes in SNAP benefits could impact food purchasing and dietary intake for low-income populations. Future research should examine how minimum wage ordinances impact usage of and eligibility for government food assistance programs.

Our results are similar to studies from the health and economics literature demonstrating that minimum wage policies are associated with increases hourly wage. ${ }^{(40-43)}$ However, unlike these studies, we did not find that the policy was associated with changes in household income. This is most likely because our study uses data from only baseline and the first year of the Minneapolis policy's implementation. Thus, it is possible that hourly wages have not yet have increased enough to translate to changes in household income between the cities. Our results are also similar to Horn et al. ${ }^{(9)}$ in that there was no association between minimum wage increases and $\mathrm{F} \& \mathrm{~V}$ consumption for women; however, we found no association, rather than an inverse association, for $\mathrm{F} \& \mathrm{~V}$ consumption in men. Our results were also dissimilar from Ukert et al. ${ }^{(10)}$ and Clark et al. ${ }^{(11)}$ in that Ukert et al. found an inverse association between minimum wage increases and $\mathrm{F} \& \mathrm{~V}$ consumption, whereas Clark et al. found a positive association. Again, our results are most likely dissimilar from these studies because the differential wage increases in the first phase of phased minimum wage policy (which in this case equated to less than a $\$ 1.00$ more than the comparison area) may not have been large enough to produce changes in dietary intake.

This study has several limitations. First, the NCI DSQ dietary screener assumes a standard portion size for all participants. Although portion sizes could vary among participants, validation studies have shown close agreement when comparing mean values from nutrients 
and food groups between the DSQ and 24-hour recall data for both males and females. ${ }^{(15)}$ Thus, the DSQ is a valid tool for assessing dietary intake for the Wages Study. Additionally, the research team did not schedule a participant's Wave 2 appointment based on the timing of their Wave 1 appointment (as this may have harmed the study's retention rate). Study participants could therefore complete their Waves 1 and 2 appointments at different times of the year. Thus, seasonality may have impacted their responses to various DSQ items between waves (for example, perhaps fruit was in season at their Wave 1 appointment in July, but not at their Wave 2 appointment in October). The study's dietary intake data may therefore have been "muddied" by these potential seasonality effects. However, the majority of data collection occurred during the summer at both sites in both waves, so the season effect is likely to be minimal. An additional limitation is that the Wages Study had considerable attrition from Wave 1 to Wave 2. However, this attrition rate is similar to attrition rates in other non-clinical cohort studies containing low-income study populations with high rates of racial/ethnic minorities. ${ }^{(44)}$

This study also has several strengths. First, the research team collected data on individual wages using an objective measure for the majority of our sample. We could therefore calculate the precise "wage dose" received for each participant in the study. This is a significant improvement over previous minimum wage studies that have used proxy measures such as educational attainment and household income to estimate the likelihood of being affected by minimum wage increases. ${ }^{(9-11)}$ Additionally, no prospective longitudinal studies have evaluated the impact of a minimum wage increase on dietary outcomes among adults. Unlike previously conducted cross-sectional studies, our longitudinal data from a natural experiment design allows us to track the same participants throughout the phased implementation of the Minneapolis ordinance, which allows us to determine individual changes in health and economic indicators over time.

\section{Conclusions:}

Through this study, we found that after the first phase of implementation, a policy-mandated minimum wage increase was not associated with changes in daily frequency of consumption of $\mathrm{F} \& \mathrm{~V}$, whole grain-rich foods, or foods high in added sugars among low-wage workers in Minneapolis compared to low-wage workers in Raleigh. However, the policy was associated with increases in hourly wage between the cities after one year of implementation. We did not detect changes in overall household income categories following the first phase of implementation, which may explain the lack of significant changes in dietary intake in our sample. However, as the minimum wage increase has not been fully implemented, it is possible that the planned increases could have greater effects. Therefore it will be important to reexamine the questions addressed in this study once full implementation has occurred. Ultimately, the question is whether minimum wage ordinances are likely to improve diet quality for low-wage workers, or whether other policy changes are needed. Additionally, improving dietary intake is not the main goal of minimum wage ordinances. Future research should evaluate the ordinance based on other health and economic outcomes. 


\section{Supplementary Material}

Refer to Web version on PubMed Central for supplementary material.

\section{Acknowledgements:}

We thank Emily Welle, Claire Sadeghzadeh, the Wages data collectors, Dr. Lisa Harnack, and Dr. Aryn Phillips for their assistance with this project.

Financial Support: This research was supported by the National Institute of Diabetes and Digestive and Kidney Diseases (NIDDK) of the National Institutes of Health (1R01DK118664-01). National Institutes of Health grant UL1TR000114 from the National Center for Advancing Translational Sciences (NCATS) supported data management. Alice S. Ammerman's role in the research reported in this publication was supported by the U.S. Centers for Disease Control and Prevention (CDC) under Award Number U48DP006400. Seth A. Berkowitz's role in the research reported in this publication was supported by the National Institute Of Diabetes And Digestive And Kidney Diseases of the National Institutes of Health under Award Number K23DK109200. NIDDK, CDC, and NCATS had no role in the design, analysis or writing of this article. The content is solely the responsibility of the authors and does not necessarily represent the official views of the National Institutes of Health.

\section{References:}

1. Lee-Kwan SH, Moore LV, Blanck HM, et al. (2017) Disparities in State-Specific Adult Fruit and Vegetable Consumption - United States, 2015. MMWR Morb Mortal Wkly Rep 66, 1241-1247. [PubMed: 29145355]

2. Fang Zhang F, Liu J, Rehm CD, et al. (2018) Trends and Disparities in Diet Quality Among US Adults by Supplemental Nutrition Assistance Program Participation Status. JAMA Netw Open. Published online: 15 June 2018. doi: 10.1001/jamanetworkopen.2018.0237

3. Satia JA (2009) Diet-related disparities: understanding the problem and accelerating solutions. J Am Diet Assoc 109, 610-615. [PubMed: 19328255]

4. Darmon N \& Drewnowski A (2015) Contribution of food prices and diet cost to socioeconomic disparities in diet quality and health: a systematic review and analysis. Nutr Rev 73, 643-660. [PubMed: 26307238]

5. Pechey R \& Monsivais P (2016) Socioeconomic inequalities in the healthiness of food choices: Exploring the contributions of food expenditures. Prev Med 88, 203-209. [PubMed: 27095324]

6. Economic Policy Institute (2019) Raising the federal minimum wage to $\$ 15$ by 2024 would lift pay for nearly 40 million workers. https://www.epi.org/publication/raising-the-federal-minimum-wageto-15-by-2024-would-lift-pay-for-nearly-40-million-workers (accessed August 2020).

7. United States Department of Agriculture (2003) International Evidence on Food Consumption Patterns. https://www.ers.usda.gov/webdocs/publications/47429/14755_tb1904_1_.pdf?v=0 (accessed July 2020).

8. University of California Giannini Foundation of Agricultural Economics (2011) Demand for Food in the United States: A Review of Literature, Evaluation of Previous Estimates, and Presentation of New Estimates of Demand. https://s.giannini.ucop.edu/uploads/ giannini_public/54/99/54994570-7739-4f54-99d7-91dd4aca3762/48-fooddemand.pdf (accessed July 2020).

9. Horn BP, Maclean JC, Strain MR (2017) Do minimum wage increases influence worker health? Econ Inq 55, 1986-2007.

10. Andreyeva E \& Ukert B (2018) The impact of the minimum wage on health. Int J Health Econ Manag 18, 337-375. [PubMed: 29516331]

11. Clark KL, Pohl RV, Thomas RC (2020) Minimum wages and healthy diet. Contemp Econ Policy 38, 546-560.

12. City of Minneapolis (2017) City's minimum wage ordinance takes effect Jan. 1, 2018. http:// news.minneapolismn.gov/2017/12/11/citys-minimum-wage-ordinance-takes-effect-jan-1-2018 (accessed August 2020). 
13. Shanafelt A, Sadeghzadeh C, Chapman LE, et al. Successful recruitment of low wage workers for a time sensitive natural experiment to evaluate a living wage policy: challenges and lessons learned. Sage Field Methods. [In Press].

14. National Cancer Institute, Division of Cancer Control \& Population Sciences (2018) Dietary Screener Questionnaires (DSQ) in the NHANES 2009-10: DSQ. https://epi.grants.cancer.gov/ nhanes/dietscreen/questionnaires.html (accessed August 2020).

15. Thompson FE, Midthune D, Kahle L, et al. (2017) Development and Evaluation of the National Cancer Institute's Dietary Screener Questionnaire Scoring Algorithms. J Nutr 147, 1226-1233. [PubMed: 28490673]

16. Nour M, Lutze SA, Grech A, et al. (2018) The Relationship between vegetable intake and weight outcomes: a systematic review of cohort studies. Nutrients 10, 1626.

17. Maki KC, Palacios OM, Koecher K, et al. (2019) The relationship between whole grain intake and body weight: results of meta-analyses of observational studies and randomized controlled trials. Nutrients 11, 1245.

18. Faruque S, Tong J, Lacmanovic V, et al. (2019) The dose makes the poison: sugar and obesity in the United States - a review. Pol J Food Nutr Sci 69, 219-233. [PubMed: 31938015]

19. Malik VS, Schulze MB, Hu FB (2006) Intake of sugar-sweetened beverages and weight gain: a systematic review. Am J Clin Nutr 84, 274-288. [PubMed: 16895873]

20. Boeing H, Bechthold A, Bub A, et al. (2012) Critical review: vegetables and fruit in the prevention of chronic diseases. Eur J Nutr 51, 637-663. [PubMed: 22684631]

21. Seal CJ \& Brownlee IA (2015) Whole-grain foods and chronic disease: evidence from epidemiological and intervention studies. Proc Nutr Soc 74, 313-319. [PubMed: 26062574]

22. Khan TA \& Sievenpiper JL (2016) Controversies about sugars: results from systematic reviews and meta-analyses on obesity, cardiometabolic disease and diabetes. Eur J Nutr 55, Suppl. 2, 25-43. [PubMed: 27900447]

23. U.S. Food and Drug Administration (2020) Added sugars on the new nutrition facts label. https:// www.fda.gov/food/new-nutrition-facts-label/added-sugars-new-nutrition-facts-label (accessed July 2020).

24. U.S. Food and Drug Administration (2013) A food labeling guide, guidance for industry. https:// www.fda.gov/files/food/published/Food-Labeling-Guide-\%28PDF\%29.pdf (accessed July 2020).

25. Gupta CC, Coates AM, Dorrian J, et al. (2019) The factors influencing the eating behaviour of shiftworkers: what, when, where and why. Ind Health 57, 419-453. [PubMed: 30404995]

26. Kinzig AP, Ehrlich PR, Alston LJ, et al. (2013) Social norms and global environmental challenges: the complex interaction of behaviors, values, and policy. Bioscience 63, 164-175. [PubMed: 25143635]

27. Zhou H, Taber C, Arcona S, et al. (2016) Difference-in-differences method in comparative effectiveness research: utility with unbalanced groups. Appl Health Econ Health Policy 14, 419429. [PubMed: 27371369]

28. Center for Disease Control and Prevention (2018) SMART: BRFSS City and County Data and Documentation. https://www.cdc.gov/brfss/smart/Smart_data.htm (accessed September 2020).

29. Cameron AC \& Trivedi PK (1986) Econometric models based on count data: comparisons and applications of some estimators and tests. J Appl Econom 1, 29-53.

30. Hausman J, Hall BH, Griliches Z (1984) Econometric models for count data with an application to the patents-R\&D relationship. Econometrica 52, 909.

31. Johnson S \& Kotz N (1969) Discrete Distributions, Houghton-Mifflin, Boston.

32. Diggle PJ, Liang KY, Zeger SL (1994) Analysis of Longitudinal Data, Oxford Science, Oxford.

33. Munafò MR, Tilling K, Taylor AE, et al. (2018) Collider scope: when selection bias can substantially influence observed associations. Int J Epidemiol 47, 226-235. [PubMed: 29040562]

34. Robins JM, Rotnitzky A, Zhao LP (1995) Analysis of semiparametric regression models for repeated outcomes in the presence of missing data. J Am Stat Assoc 90,106-121.

35. Robins JM. Marginal structural models versus structural nested models as tools for causal inference. In Statistical Models in Epidemiology: The Environment and Clinical Trials, Halloran ME, Berry D (eds). IMA Volume 116, Springer-Verlag: New York, 1999; 95-134. 
36. Robins JM, Hernan MA, Brumback B (2000) Marginal structural models and causal inference in epidemiology. Epidemiology 11, 550-560. [PubMed: 10955408]

37. St. Jude.org (2009) Childhood Cancer Survivor Study Analysis Concept Proposal. https:// ccss.stjude.org/content/dam/en_US/shared/ccss/documents/concept-prop/concept-prop-11-09.pdf (accessed July 2020).

38. U.S. Bureau of Labor Statistics (2015) Same occupation, different pay: how wages vary. https:// www.bls.gov/careeroutlook/2015/article/wage-differences.htm (accessed July 2020).

39. Pew Research Center (2016) Racial, gender wage gaps persist in U.S. despite some progress https://www.pewresearch.org/fact-tank/2016/07/01/racial-gender-wage-gaps-persist-in-u-s-despitesome-progress/ (accessed July 2020).

40. Economic Policy Institute (2019) Raising the federal minimum wage to $\$ 15$ by 2024 would lift pay for nearly 40 million workers. https://www.epi.org/publication/raising-the-federal-minimum-wageto-15-by-2024-would-lift-pay-for-nearly-40-million-workers/ (accessed June 2020).

41. Institute for Research on Labor and Employment (2019) Minimum wage effects in low-Wage Areas. https://irle.berkeley.edu/minimum-wage-effects-in-low-wage-areas/ (accessed August 2020).

42. Congressional Budget Office (2019) The Effects on Employment and Family Income of Increasing the Federal Minimum Wage. https://www.cbo.gov/system/files/2019-07/CBO-55410MinimumWage2019.pdf (accessed August 2020).

43. National Bureau of Economic Research (2018) Minimum wages and the distribution of family incomes. https://www.nber.org/papers/w25240.pdf (accessed August 2020).

44. Teague S, Youssef GJ, Macdonald JA, et al. (2018) Retention strategies in longitudinal cohort studies: a systematic review and meta-analysis. BMC Med Res Methodol 18, 151. [PubMed: 30477443] 


\begin{tabular}{|c|c|c|}
\hline Date & $\begin{array}{l}\text { Large Businesses } \\
\text { (>100 employees) }\end{array}$ & $\begin{array}{l}\text { Small Businesses } \\
\text { ( } \leq 100 \text { employee })\end{array}$ \\
\hline 2017 & $\$ 9.50$ & $\$ 7.75$ \\
\hline $\begin{array}{c}\text { January 1, } 2018 \\
\text { (Wages Study baseline (Wave 1) data collection begins) }\end{array}$ & $\$ 10.00$ & No increase \\
\hline July 1, 2018 & $\$ 11.25$ & $\$ 10.25$ \\
\hline $\begin{array}{c}\text { July 1, } 2019 \\
\text { (Wages Study Wave 2 data collection begins) }\end{array}$ & $\$ 12.25$ & $\$ 11.00$ \\
\hline $\begin{array}{c}\text { July 1, } 2020 \\
\text { (Wages Study Wave } 3 \text { data collection begins) }\end{array}$ & $\$ 13.25$ & $\$ 11.75$ \\
\hline $\begin{array}{c}\text { July 1, } 2021 \\
\text { (Wages Study Wave } 4 \text { data collection begins) }\end{array}$ & $\$ 14.25$ & $\$ 12.50$ \\
\hline $\begin{array}{c}\text { July 1, } 2022 \\
\text { (Wages Study Wave } 5 \text { data collection begins) }\end{array}$ & $\$ 15.00^{*}$ & $\$ 13.50$ \\
\hline July 1, 2023 & $\$ 15.00 *$ & $\$ 14.50$ \\
\hline July 1, 2024 & $\$ 15.00 *$ & $\begin{array}{c}\$ 15.00^{*} \\
\text { (Equal to Large Businesses) }\end{array}$ \\
\hline
\end{tabular}

Figure 1.

Scheduled implementation of hourly wage increases in the city of Minneapolis, and the corresponding Wages Study data collection time points.

*Increases to account for inflation, every subsequent January 1st. 


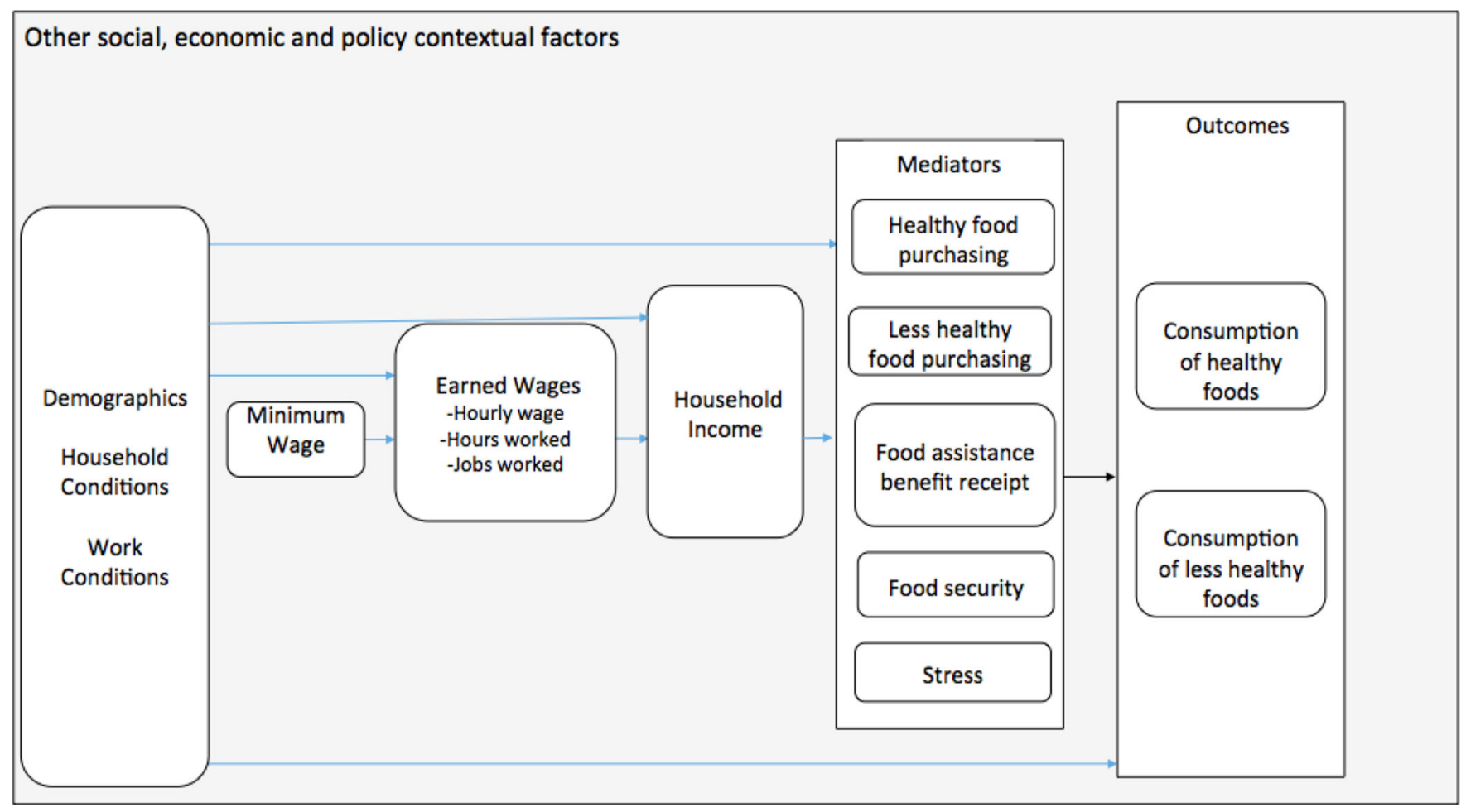

Figure 2.

Conceptual model for the present study using data from Wave 1 (2018) and Wave 2 (2019) the Wages Study. 


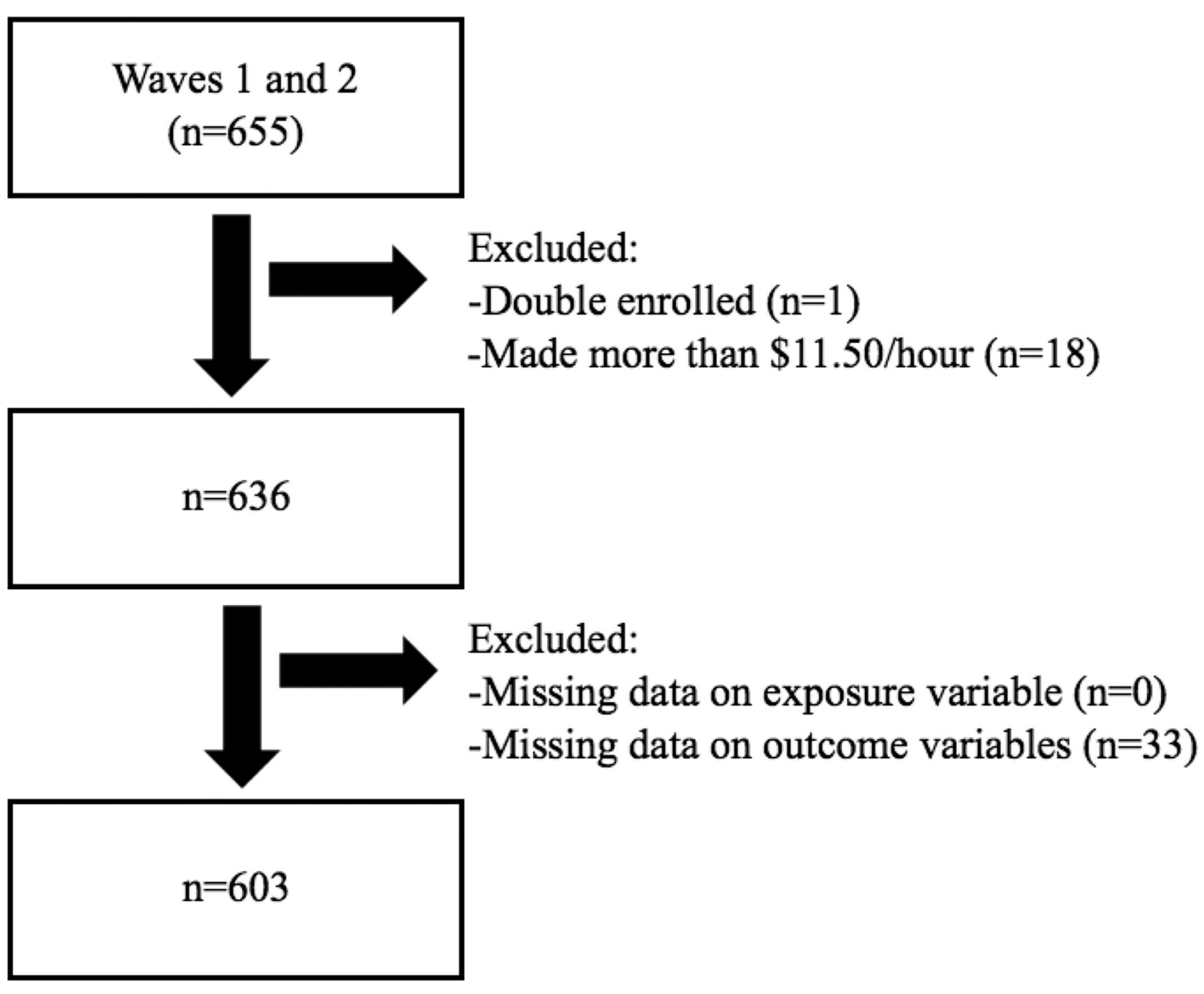

Figure 3.

Flow chart for Wages participant exclusion in the present study's policy analyses. 
Waves 1 and 2 $(\mathrm{n}=655)$

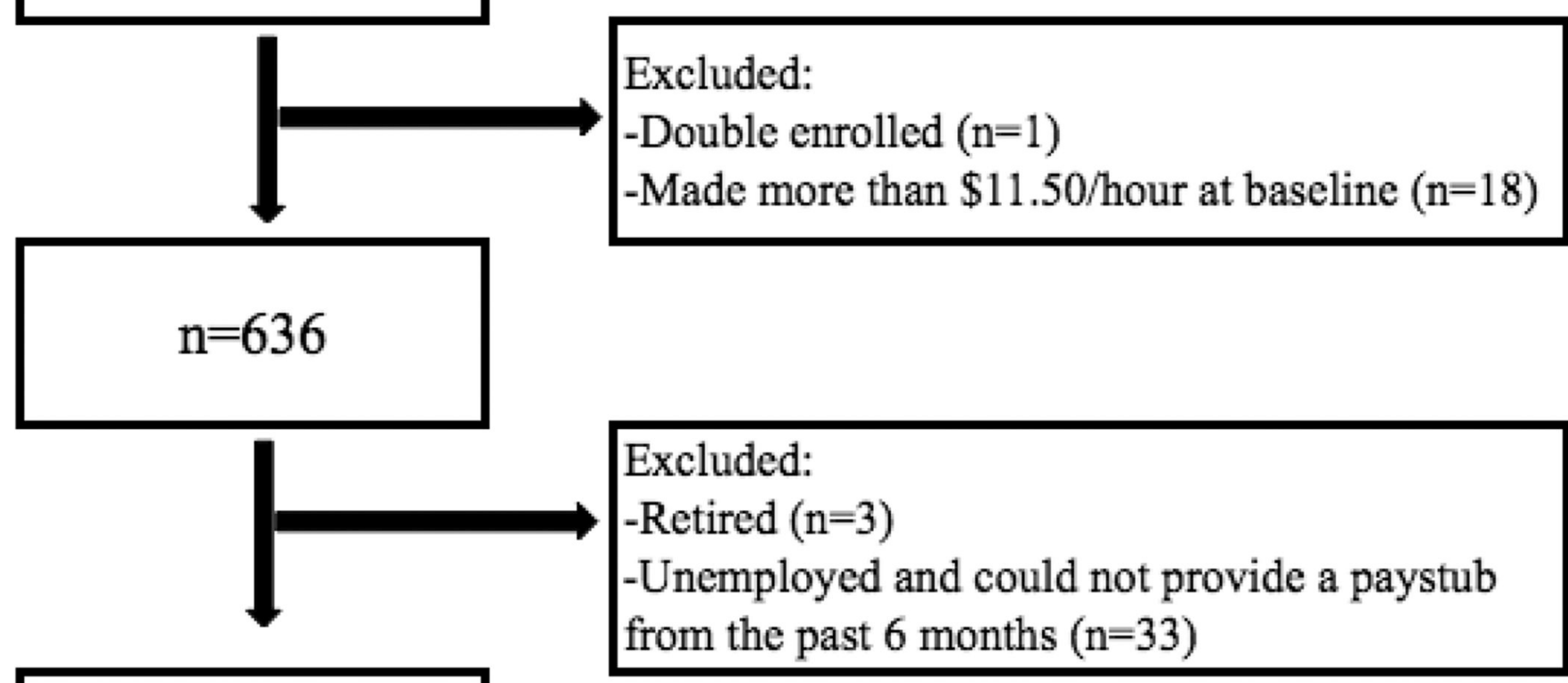

$\mathrm{n}=600$

Excluded:

-Missing data on exposure variable $(\mathrm{n}=27)$

-Missing data on outcome variables $(\mathrm{n}=33)$

\section{$\mathrm{n}=540$}

Figure 4.

Flow chart for Wages participant exclusion in the present study's hourly wage analyses. 

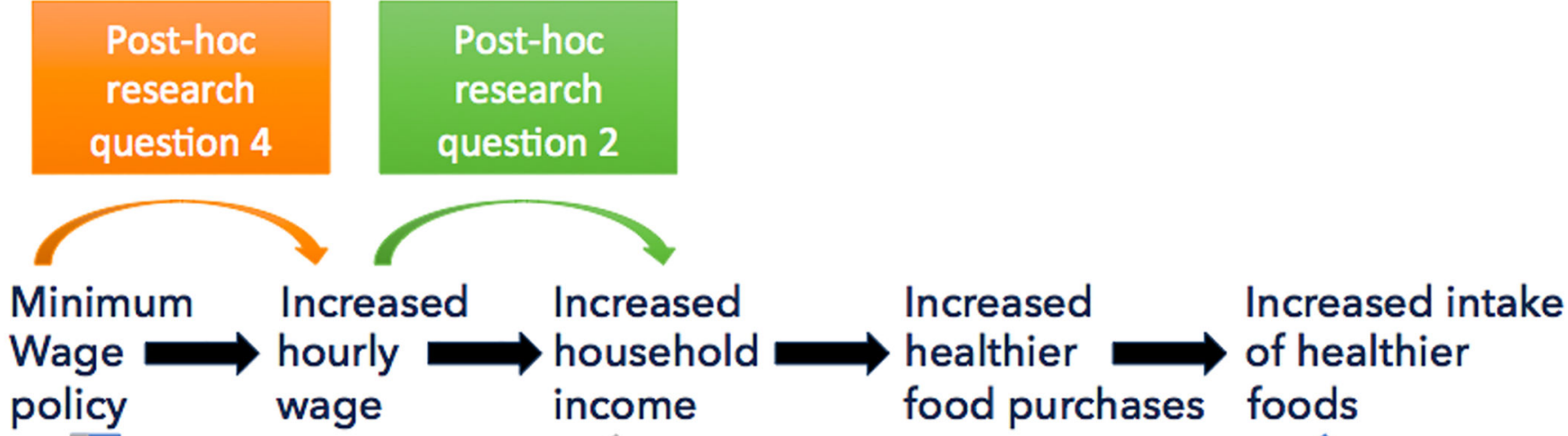

Post-hoc

research

question 5

\section{Primary aim of}

present study

Figure 5.

Hypothesized causal pathway for the relationship between a minimum wage policy and changes in dietary intake.

*Note: Post-hoc research question 1 and 3 are not depicted on the above diagram because they did not test relationships between variables. They were based on data tabulations and unadjusted difference-in-difference regressions. 

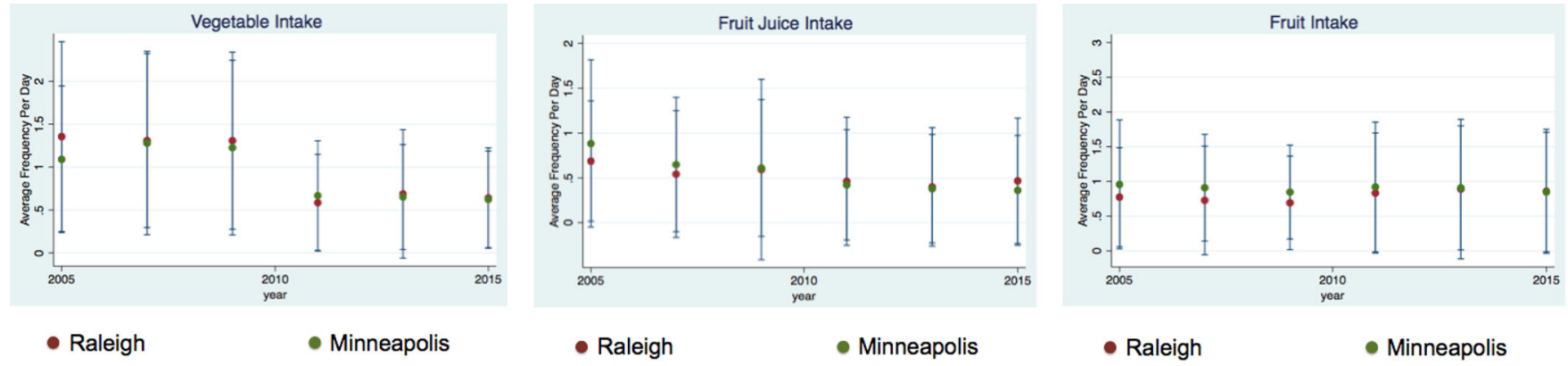

Figure 6.

Dietary intake by metropolitan statistical area 2005-2015 BRFSS SMART data - incomes < $\$ 35,000$ per year.

*Bars are standard deviations. 
로을

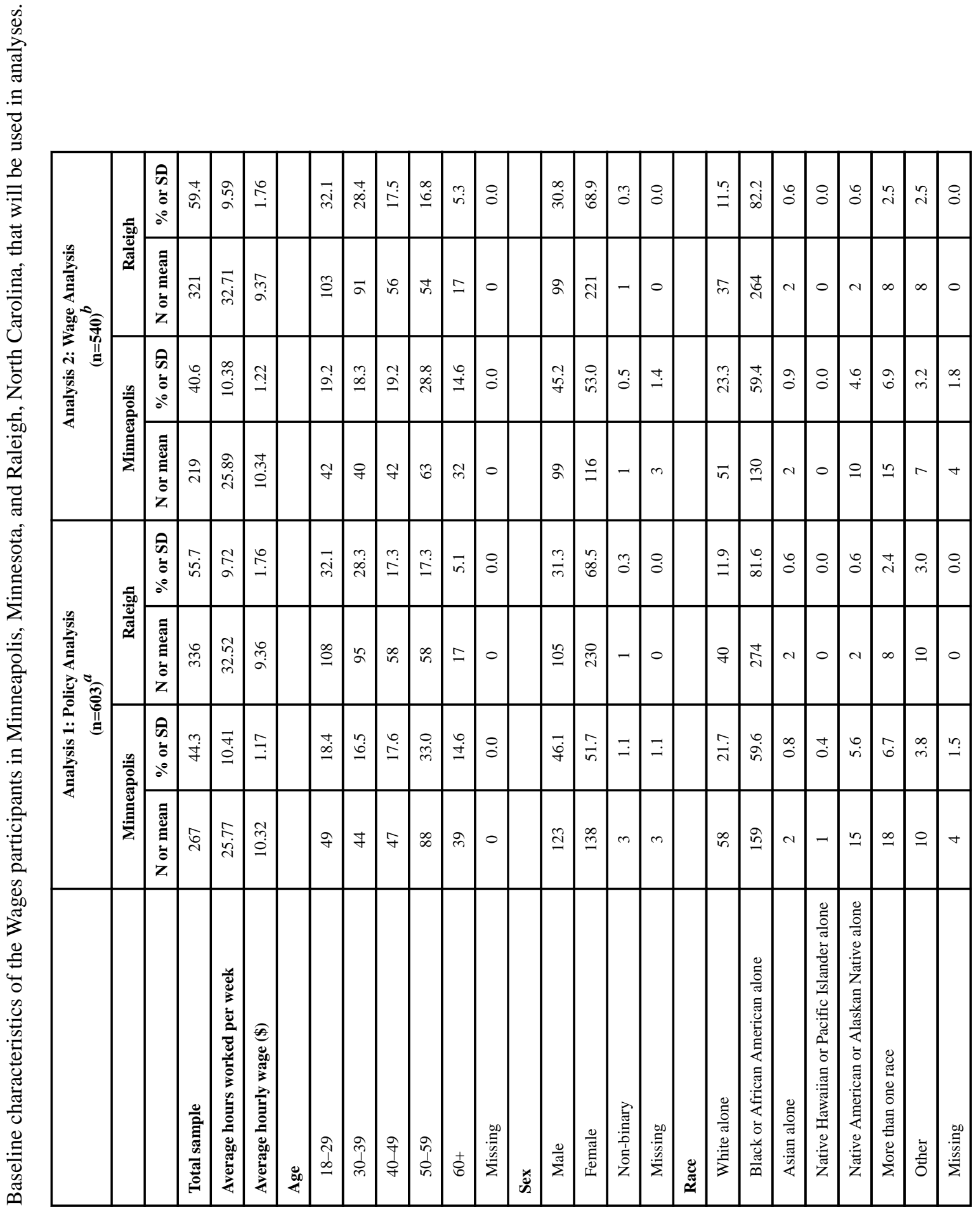

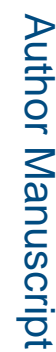

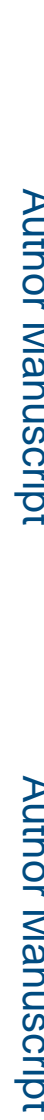

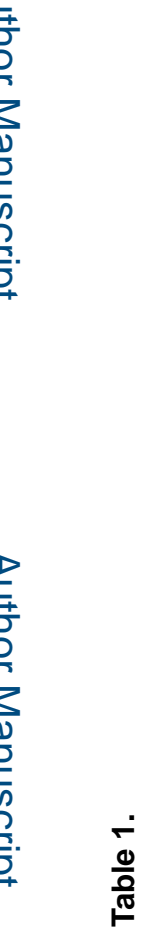

旁

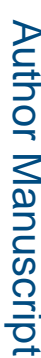

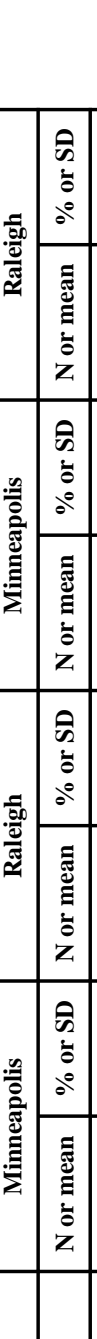




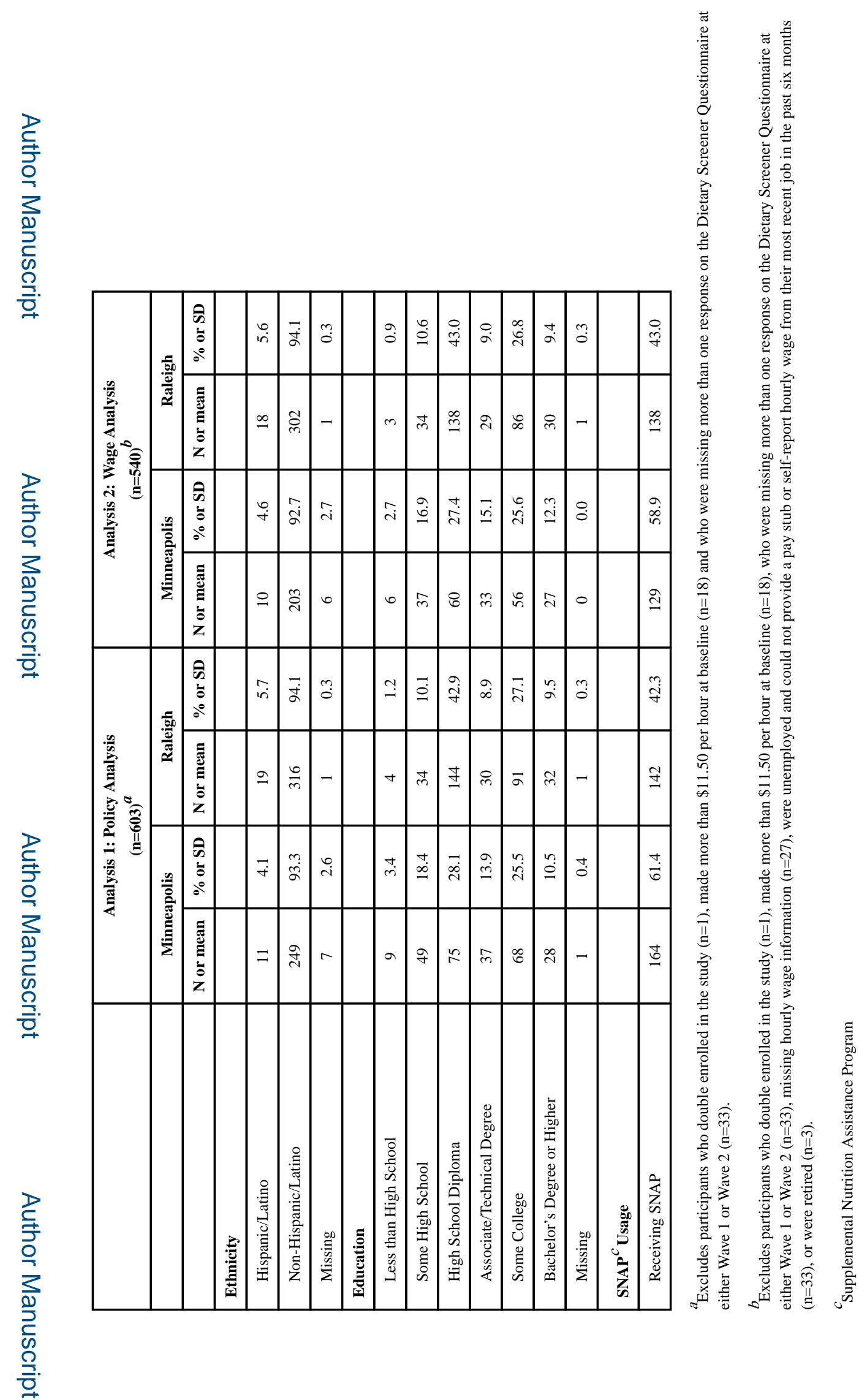

Public Health Nutr. Author manuscript; available in PMC 2022 August 01. 


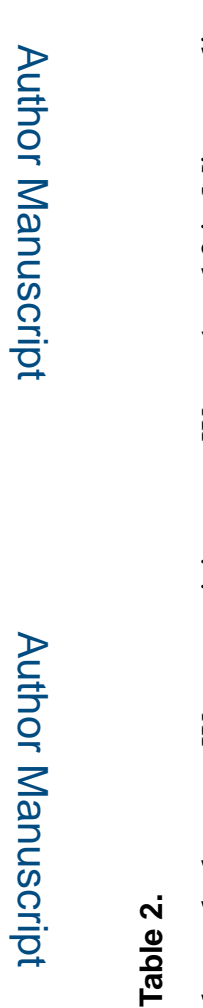

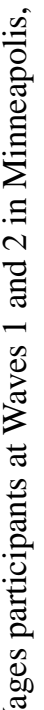

3

о

สิ ชิ

ำ

을

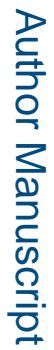

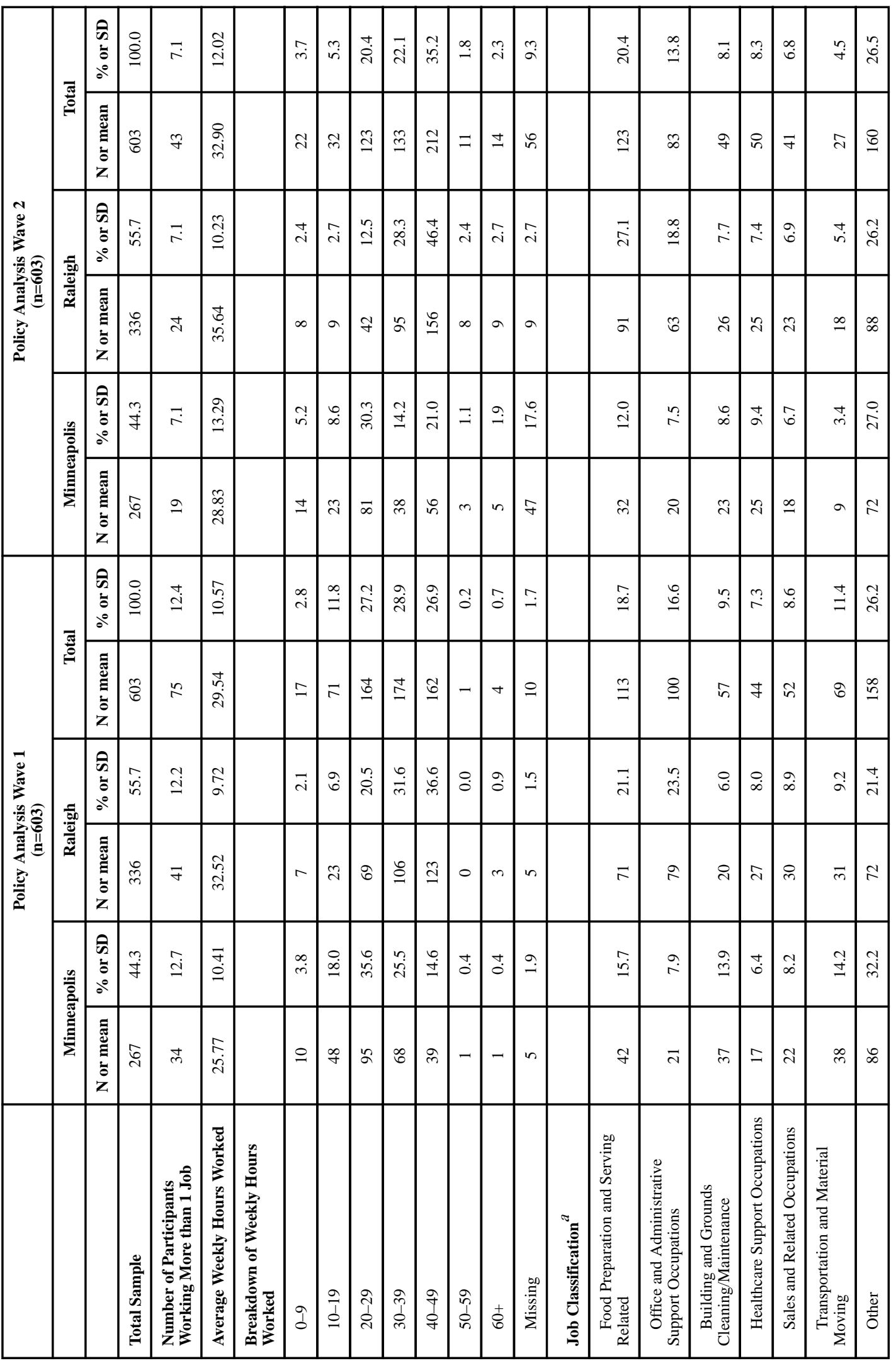

Public Health Nutr. Author manuscript; available in PMC 2022 August 01. 


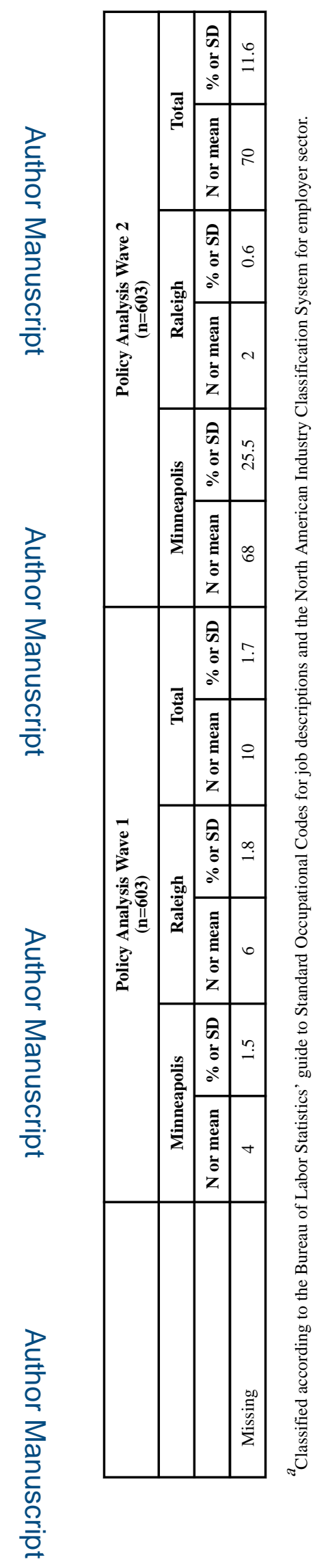

Public Health Nutr. Author manuscript; available in PMC 2022 August 01. 


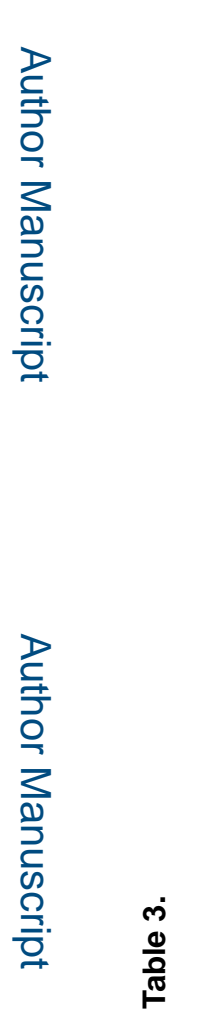

롤

을

要

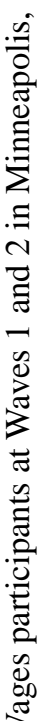

3 宇

छั

$\frac{n}{\infty}$

:

嵌

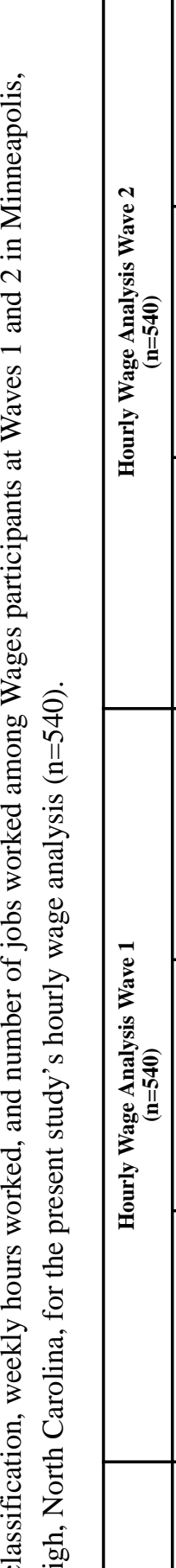

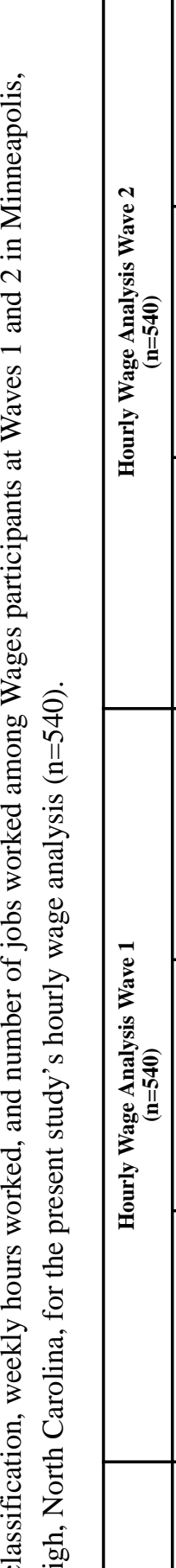

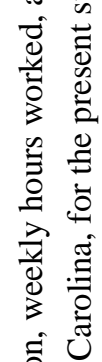

莺

空

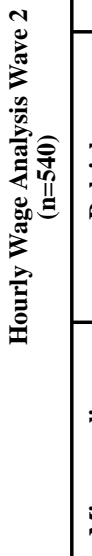

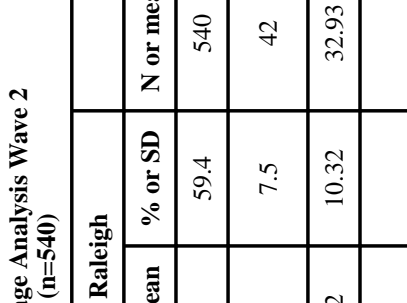

$\approx$ 节

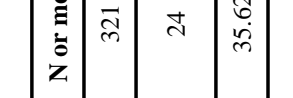

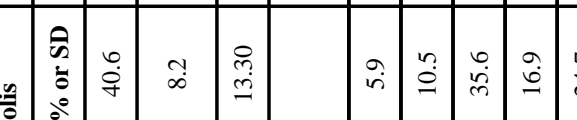

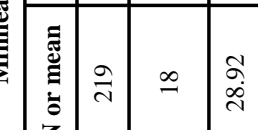

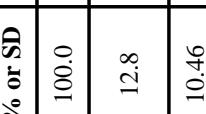

吾

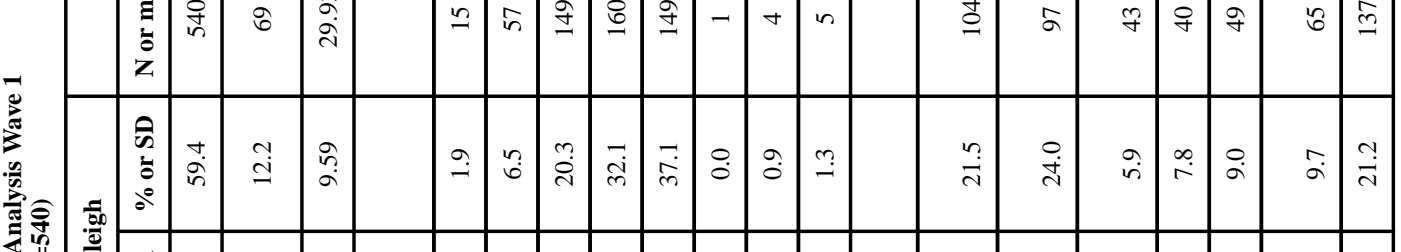

|

政

离

$$
\begin{array}{llll|l|l} 
& & & & & \\
& 0 & & & &
\end{array}
$$

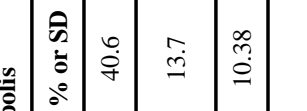

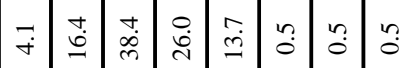

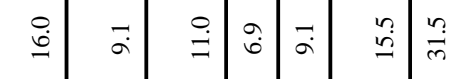

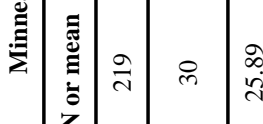

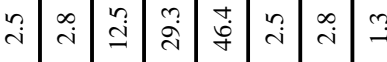

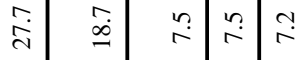

के तु 


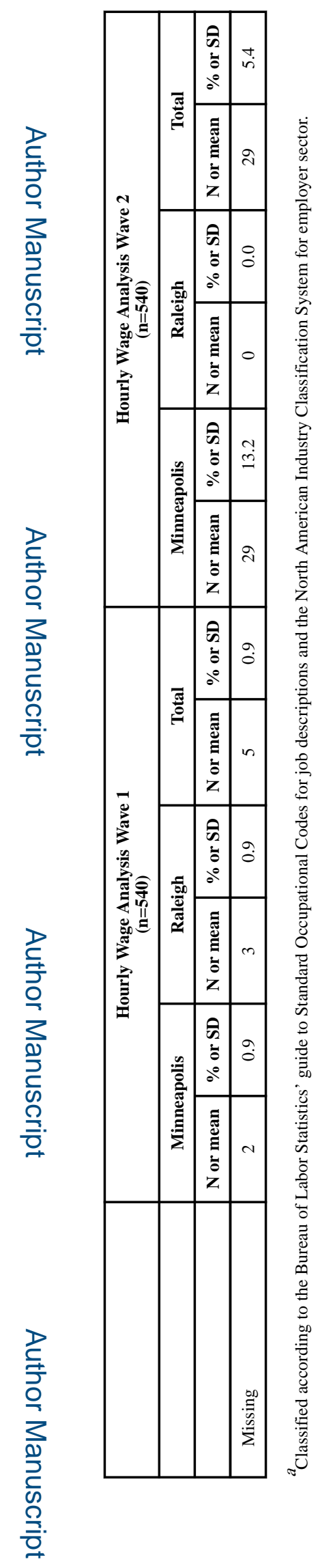

Public Health Nutr. Author manuscript; available in PMC 2022 August 01. 


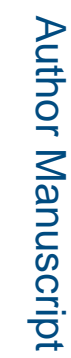

胥

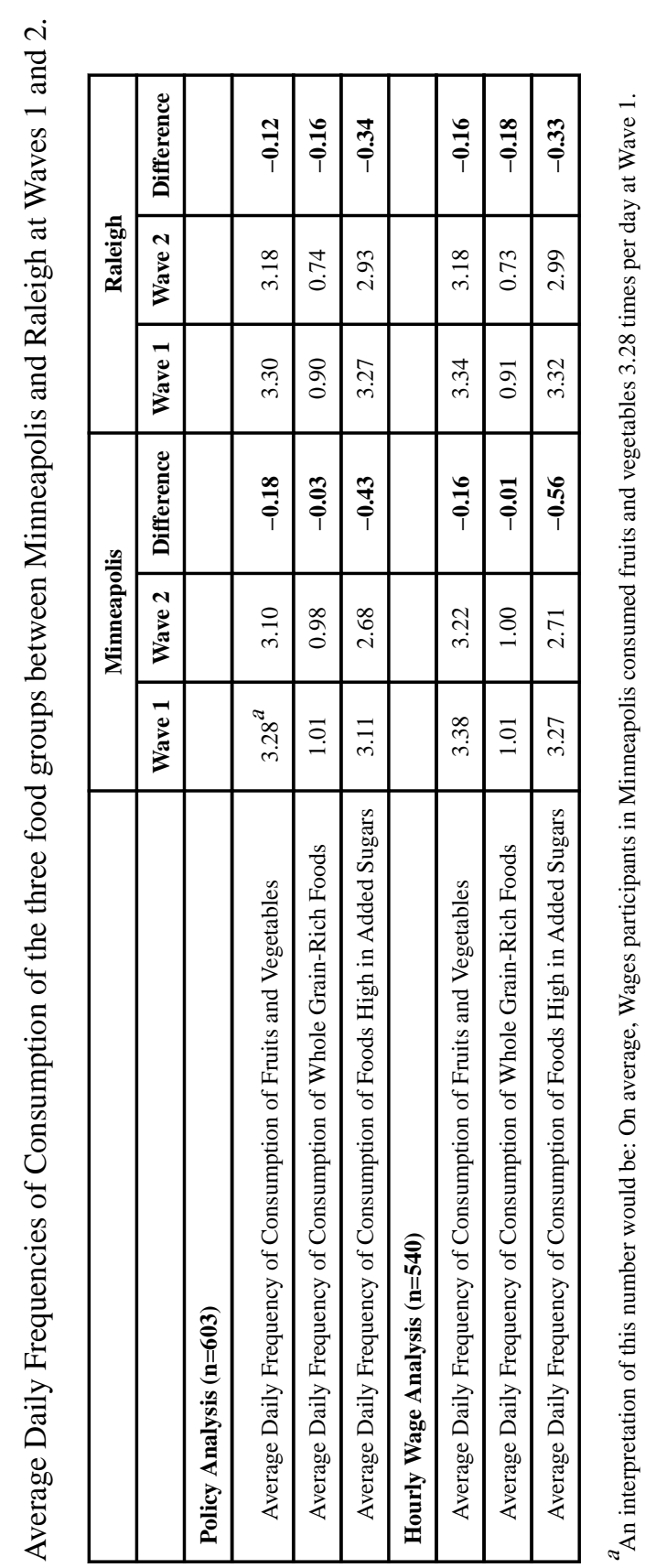

Public Health Nutr. Author manuscript; available in PMC 2022 August 01. 


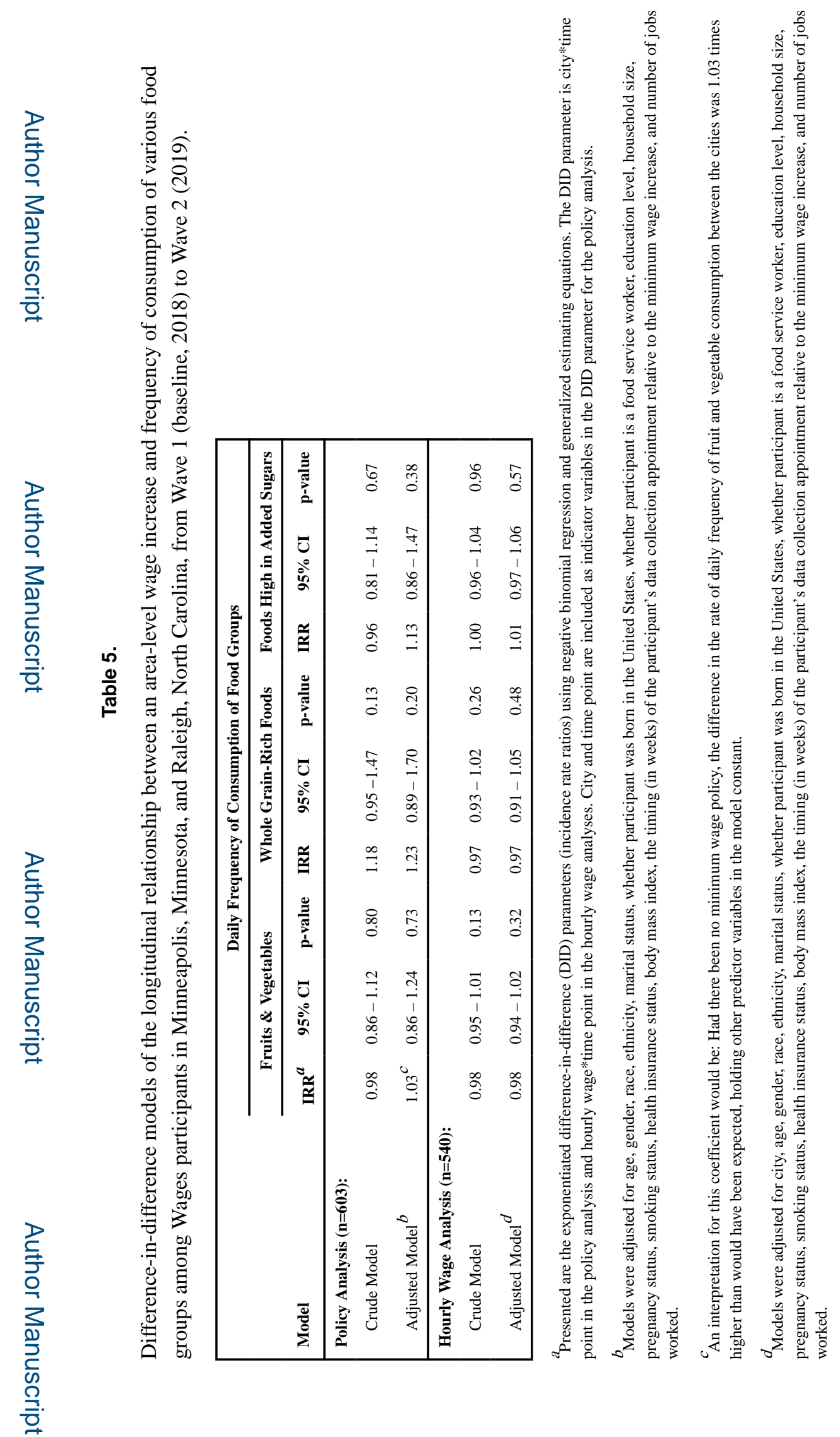

Public Health Nutr. Author manuscript; available in PMC 2022 August 01. 


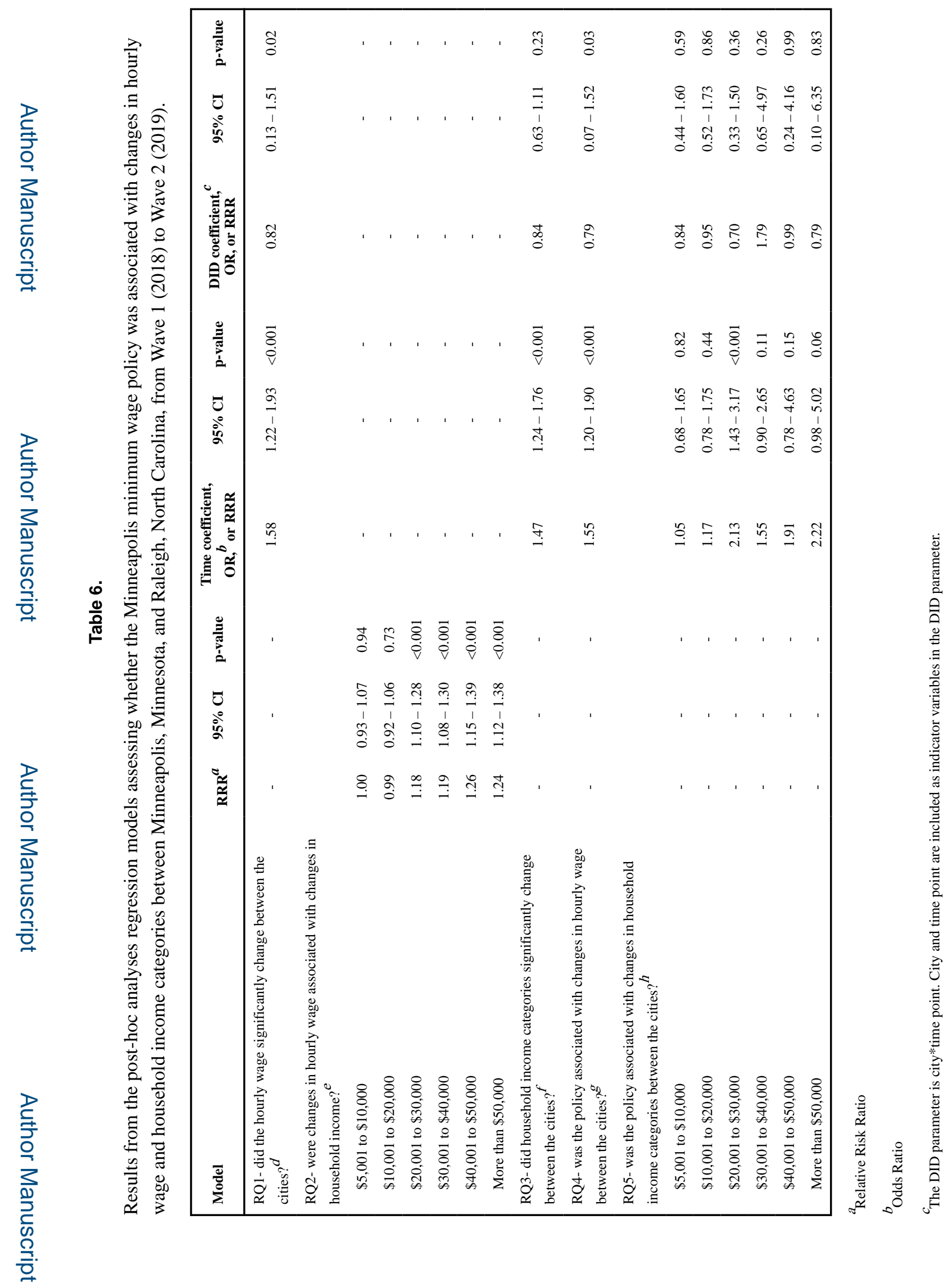

Public Health Nutr. Author manuscript; available in PMC 2022 August 01. 


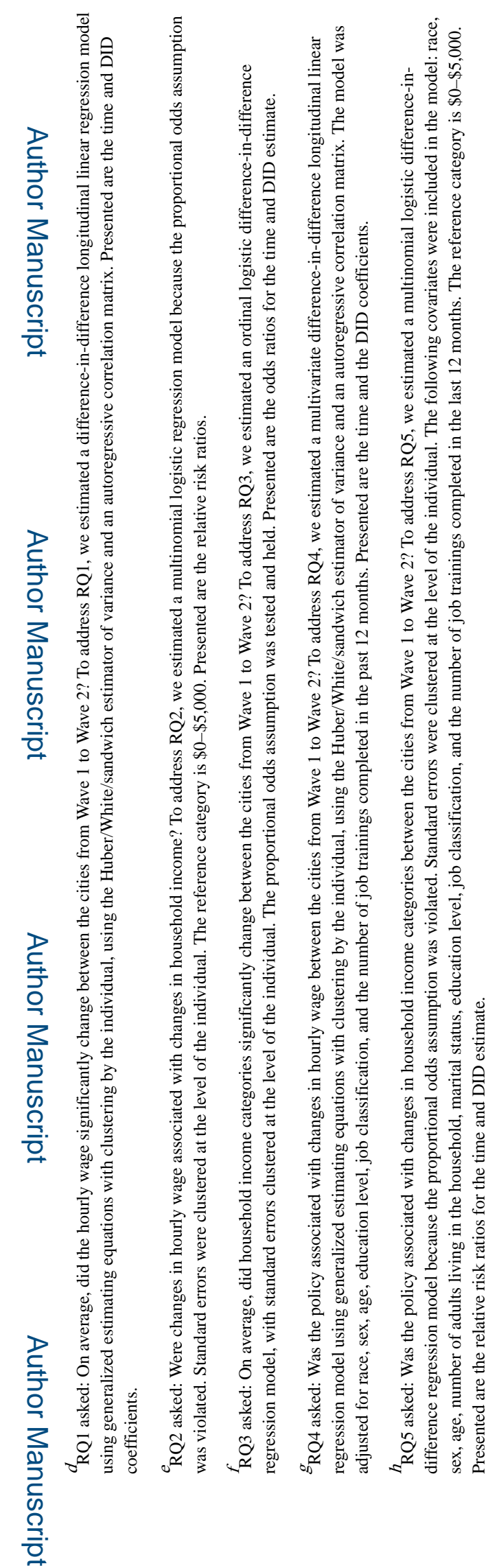

Public Health Nutr. Author manuscript; available in PMC 2022 August 01. 